\title{
The Effect of Index Model Rating on the Representativeness of the Indicators of the Quality of the Student's Education
}

\author{
M.V. Mardanov \\ MVMardanov@kpfu.ru \\ J.V. Zhiglij \\ Kazan Federal University, Institute of Management, Economics and Finance, Kazan, 420008, Russia \\ Juliya.Zhiglij@kpfu.ru
}

\section{Doi:10.5901/mjss.2015.v6n3p714}

\section{Abstract}

The article considers the index model of rating the quality of the student's education. The results of the expert evaluation of the final ratings of indicators of quality of training of the students, built on traditional and index models. In accordance with the adopted at this work, the methodological approach of integral indexes, reflecting the development of students' knowledge of the discipline, their professional competences are calculated as the geometric average of the indices of changes of different indicators of the status and development. Special attention in the experiment is paid on the evaluation of experts of the representativeness of the obtained results.

Keywords: rating, quality, index, representative, expert evaluation, qualimetry, student's education, index model rating.

\section{Introduction}

The process of integration of the Russian system of the professional education in the international education has led to the need for continuous improvement of quality and efficiency of education, regular updates of its content and methodology, the implementation of innovative approaches and technologies, the introduction of the international standards for the material and technical provisions of the educational process, the development of a unified foreign and internal control system and evaluation of students' knowledge. Confirmation of this fact is the formation of a national Russian system of monitoring and evaluation of the quality of education in accordance with the European standards, to effectively manage of the ongoing educational policy.

The introduction of index qualimetry, using the quality measures which were obtained when they were normalized on the basis of the index, at the point-rating system makes a more objective evaluation of the students' progress in general. It allows you to rate total academic progress of the student and to give a deeper analysis of the training results and formation of the competences, to rate those ranges of activity of the student, which may not be comprised with the academic mark and it focuses the student's attention to the most important activities.

\section{Results}

When developing an index model rating we were based on the facts that we can constrict the using of qualimetry up to the evaluation of the index of the individual properties or we can expand up to quantify of the immeasurable objects, trying to give a comprehensive evaluation.

Qualimetry is an interconnected system of theories of various degrees of generality. Among the theories can be concerned $[3,6,11]$ :

- general qualimetry, considering the system of concepts, theory, measurement and evaluation, statistical theory of scales;

- $\quad$ special qualimetry (methods and models of marks), these include [10]:

a) expert qualimetry where marks are given by experts or automated expert systems;

b) probability and statistical qualimetry, using the methods of probability theory and mathematical statistics, evaluating the homogeneity of the general totality and samples, the coincidence of the laws of distribution, 
ergodicity, marking and etc.;

c) index qualimetry, using the quality measures which are obtained when it was normalized on the basis of indexation (comparison);

d) taxonomic qualimetry (or qualitative taxonomy) based on classes of quality (quali taxon) of the objects when can be examined the type, grade, and etc. of the object and the same characteristics of the classification system;

- subjectqualimetry (subject to evaluation) of the production, work, projects, and processes.

As we have already said, we can constrict the using of qualimetry up to the evaluation of the index of the individual properties or we can expand up to quantify of the immeasurable objects, trying to give a comprehensive evaluation [9].

Thesis about qualimetry of quality of training of students through a point rating system are described in the methodical recommendations of the Ministry of education and science of the Russian Federation:

- the ordering, perspicuity and empowerment of the possibility of using of various types and forms of the current and intermediate of the quality control process and results of education;

- the formalization of the evaluation process [1];

- the implementation of the individual approach at the educational process;

- the formation of the students' motivation to the systematic working - class and self-independent;

- the encouragement of the students to the development of educational programs on the basis of objectivity and differentiation evaluation of the results of their academic work;

- the ratings of the students by the level of formation of competences, including both academic results and personal characteristics [2];

- the objective basis for the choice of students for the further studies (magistracy, graduate school), passing the semester studying abroad and employment of graduates;

- the correction by the teachers of the educational process and affection of the educational touch to the students.

Analysis of implementation experience of the point rating system allows to mark as the advantages of this system:

- provision of a comprehensive evaluation of the academic work of the students [4];

- increase the level of discipline and activity of the students, improving attendance;

- simplify of the process of assessment of the students;

- increase the objectivity of the evaluation of students' work by the teachers [7];

- more effective and early choice of the students for further research and teaching activities.

- But there are disadvantages of a point rating system:

- significant increase of the work of the teachers in checking of the control and self-independent works without extra hours of wage-rate;

- inability to grade students according to the results of the semester totally, that reduces the motivation of the students;

- the lack of mechanisms of the work with students at a high level who knows the subject very well, but they can't pass the exams (test) because they haven't enough marks, they have a great number of absences due to working;

- not developed procedures of the work with "poor" students;

- the difficulty of evaluating the quality of training, based on the quantitative results of educational activity of the students and teachers, especially at the evaluation of competence according to the new Federal educational standards [8, 12];

- the importance of working with the control and diagnostic materials having different rating scales [5].

These shortcoming points of rating system have the greatest interest of the last two problems. Evidently, the scales that were used for the testing, survey and evaluation of various activities of the students, not allow, due to their heterogeneity, to use the normal rating for evaluation at a point rating system. To resolve this problem, the normalization of the original data to the further work with them at a point rating system is required. To solve this problem, we used the index model rating.

The feature of the index model and the indices is that the indexed indicator is considered not in isolation but in conjunction with other indicators. Multiplying the indexed indicator by another, related with it, we bring different things to their unity, we provide the quantitative comparability and consider their weight in the overall evaluation of the indicator.

Thus, the actual index is a relative indicator of a special kind, in which the levels of the studied phenomenon are seen in connection with another (or others) phenomenon, the changing of the latter is fixed (eliminated). The indicators 
associated with indexed rate, are used as weights of the index, and the weigh-in and elimination of changes of scales (fixed in the numerator and denominator of the index on the same level) are the specifics of the actual indices and index method.

In accordance with the adopted at this work, the methodological approach of integral indexes, reflecting the development of students' knowledge of the discipline, their professional competences are calculated as the geometric average of the indices of changes of different indicators of the status and development.

The use of the geometric average for the compilation and analysis of integral index evaluation is determined of the following reasons:

- advantages of the geometric average are in the possibility of its use in cases when it is difficult to give preference weights, which are integral index should include specific indicators development indicators;

- this method allows to bring to a common denominator indicators are measured in different units;

- the method provides a qualitative account of individual performance, which does not show the rating and the average values of the estimates.

The final rating is calculated as the geometric mean of normalized indices in the line. As a result, the matrix of indices of "cumulative" type allows to enter a qualitative evaluation of the knowledge and competences of the students to the process and the result of diagnosis, control in training. The use of the index method when calculating the student's ratings allows us not only to quantify the student, but also to provide a qualitative evaluation of the effectiveness of his work.

The experimental methods (search, ascertaining and forming experiment), and also statistical methods for estimating rating and mathematical processing of experimental data, their system and qualitative analysis, graphics interpretation were used for evaluation of the effectiveness of the index model. Totality of used methods and their complementarity ensure the reliability of research results.

Proposed index model rating have been tested during the training of the students to multiple disciplines at the University (the Institute of Philology and intercultural communication (Department of Russian and foreign Philology by L. N. Tolstoy, Department of Russian literature and methods of teaching) and the Institute of management, Economics and Finance (economic department, Department of economic-mathematical modeling)) for several years. Registration of training progress and of the rating was carried out according to the classical system and according to the index model. Teachers participating in the expertise assessed the contentment at the final rating of the student. Statistical processing of the results of expert evaluation showed that the final rating based on the classical system has satisfied the examiners in 57\% of cases (Figure 1), while the rating, built at the index model was 78\% (Figure 2).

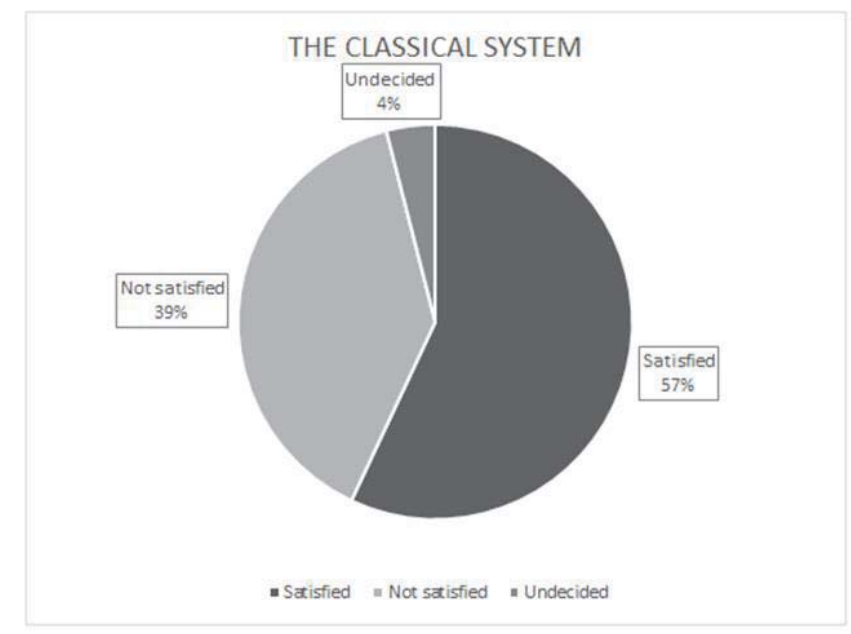

Figure 1. The Classical system 


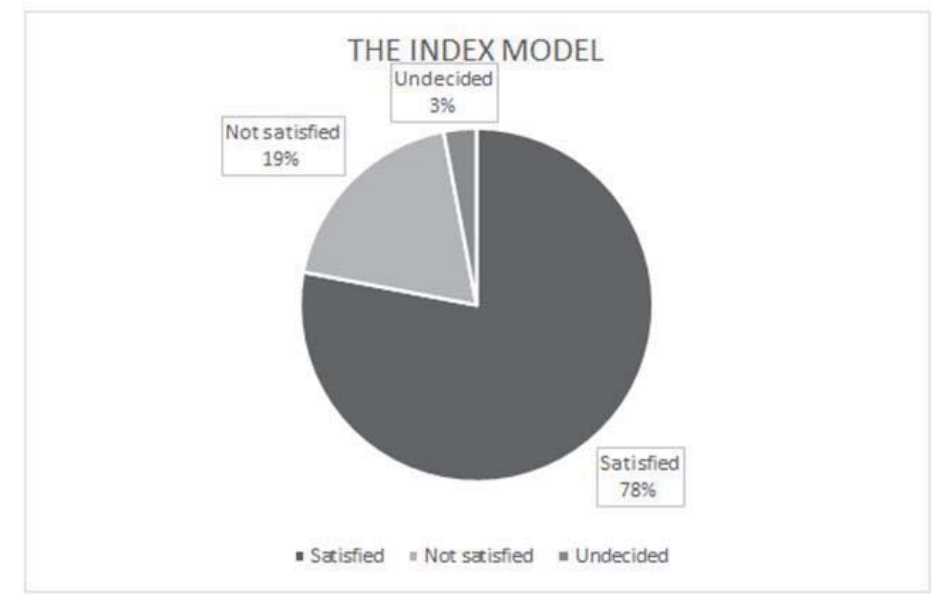

Figure 2. The index model

The analysis of the results showed that the correlation between ratings is direct, above average $(0,758)$, and the variance is quite high $(42,37)$. Control of the experimental results for the representation showed that the difference of the points is significantly different, at the same time, according to experts, the index model provides more representative evaluation of the quality of training of the students.

\section{Conclusion}

The fact of introduction of index qualimetry, using the quality measures which were obtained when they were normalized on the basis of the index, at the point-rating system makes a more objective evaluation of the students' progress in general allowing to rate the total academic progress of the student and to give a deeper analysis of the training results and formation of the competences, to rate those ranges of activity of the student, which may not be comprised with the academic mark and it focuses the student's attention to the most important activities.

\section{References}

Bezpalko, V.P. (1989) Components of educational technology (p.192). Moscow: Education.

Bezpalko, V.P. (1996) Monitoring the quality of education means education management .World education. No. 2. 31-36.

Gliches, A. B. (2009) Quality, efficiency, ethics: a manual (p.358). Moscow: Premium Engineering.

Chasanov, M. A. (2012) Flexible technology problem-modular training (p.158).Moscow: Education.

Chasanov, M. A. (2011) Engineering learning technology(p.240). Publishing house: Binom. Knowledge laboratory.

Fedyukin C. K. (2004) Fundamentals qualimetry. Moscow: Filin.

Kuzmina, N.V. (2008) Psychology quality of professional activity of the specialist: monograph. (p.375). Saint-Petersburg; Kolomna; Ryazan: Publishing house of the Ryazan regional Institute of education development.

Lednev, V. S. (2002) State educational standards in General education: theory and practice (p.276). Moscow: Vlados.

Lobanov, A. C. (2007) Quality Management on the basis of qualimetry. Ed. Second, revised and supplemented. Sochi, "Avalanche".

Ponomarev, S. C., Mishchenko, S. C., Gerasimov, B., Trofimov, I., A. (2005) Qualimetry and quality management. Tools of quality control: Training manual. Century (p.80). Moscow: Publishing house of the compromise. State technology. University.

Subetto, A. I. (1990) Introduction in qualimetry high school. Moscow: Research center Rosobrazovanie of the USSR.

Telegina, N.V., Galimova, E.G., Masalimova, A.R. (2015) The structure and content of the model of pedagogical Conditions binary approach to optimization of control and diagnostic functions in teaching "General pedagogy" to students. Asian Social Science; Vol.11; No.1, 2015, 364-368. 